\title{
The AVIATOR registry: the importance of evaluating long-term patient outcomes
}

\author{
Frederiek de Heer ${ }^{1}$, Emmanuel Lansac ${ }^{2}$, Ismail El-Hamamsy ${ }^{3}$, Philippe Pibarot ${ }^{4}$, Laurent De Kerchove ${ }^{5}$, \\ Gebrine El Khoury ${ }^{5}$, Hans-Joachim Schäfers ${ }^{6}$, Johanna J. M. Takkenberg ${ }^{7}$, Jolanda Kluin ${ }^{1}$; on behalf of \\ the Aortic Valve Repair Research Network Investigators*
}

${ }^{1}$ Department of Cardiothoracic Surgery, Academic Medical Center, Amsterdam, The Netherlands; ${ }^{2}$ Department of Cardiac Surgery, Institut Mutualiste Montsouris, Paris, France; ${ }^{3}$ Department of Cardiac Surgery, Montreal Heart Institute, Université de Montreal, Montreal, Quebec, Canada; ${ }^{4}$ Department of Cardiology, Quebec Heart \& Lung Institute, Laval University, Quebec City, Quebec, Canada; ${ }^{5}$ Department of Cardiovascular and Thoracic Surgery, Cliniques universitaires Saint-Luc, Bruxelles, Belgium; ${ }^{6}$ Department of Thoracic and Cardiovascular Surgery, Saarland University Medical Center, Homburg, Germany; ${ }^{7}$ Department of Cardiothoracic Surgery, Erasmus MC Rotterdam, Rotterdam, The Netherlands

Correspondence to: Frederiek de Heer. Department of Cardio-Thoracic Surgery, Academic Medical Center, Meibergdreef 9, 1105 AZ Amsterdam, The Netherlands. Email: f.deheer@amc.nl.

Submitted Mar 01, 2019. Accepted for publication Apr 05, 2019.

doi: 10.21037/acs.2019.04.08

View this article at: http://dx.doi.org/10.21037/acs.2019.04.08

Being a technically gifted surgeon is not enough to make you a good aortic valve repair surgeon. An additional requirement is the long-term evaluation of the treatment and comparison of your results to other surgeons. The
AVIATOR registry, outlined below, enables surgeons to evaluate their results and fulfill this requirement.

Over the past two decades, aortic valve repair has evolved as a treatment strategy in patients with aortic regurgitation

* Collaborators [122]: Christian Dinges, MD; Johannes Steindl; Rosina Ziller; Jean-Louis Vanoverschelde, MD, PhD; Taoufik Benkacem; Corinne Coulon; Fadoua Kaddouri; Christophe de Meester, MS; Agnès Pasquet, MD, PhD; Jan Nijs, MD; Veerle Van Mossevelde; Bart Loeys, MD, PhD; Bart Meuris, MD, PhD; Evi Schepmans; Klaartje Van den Bossche; Peter Verbrugghe, MD; Wenke Goossens; Herbert Gutermann, MD; Matteo Pettinari, MD; Marien Lenoir; Pierre-Emmanuel Noly; Michael Tousch; Pallav Shah, MD; Munir Boodhwani, MD, MMSc; Igor Rudez, MD, PhD; Davor Baric, MD, PhD; Daniel Unic, MD, PhD; Josip Varvodic, MD; Savica Gjorgijevska, MD; Jan Vojacek, MD, PhD; Pavel Zacek, MD, PhD; Mikita Karalko, MD; Jaroslav Hlubocky, MD; Robert Novotny; Andrey Slautin; Said Soliman, MD; Eric Arnaud-Crozat; Aude Boignard; Georges Fayad; Olivier Bouchot, MD, PhD; Bernard Albat; Alain Leguerrier; Fabien Doguet; Jean-François Fuzellier; Yves Glock; Guy Fernandez; Didier Chatel; David Messika Zeitoun, MD, PhD; Jérôme Jouan; Isabelle Di Centa, MD; Jean-François Obadia; Pascal Leprince; Rémi Houel; Eric Bergoend, MD; Stéphane Lopez; Alain Berrebi, MD; Florence Tubach, MD, PhD; Jean-Luc Monin, MD, PdH; Sarah Pousset; Laurent de Guillaume Jondeau, MD, PhD; Leila Mankoubi, MD; Milean Noghin, MD; Christelle Diakov, MD; Daniel Czytrom, MD; Michael Borger, MD, PhD; Diana Aicher, MD, PhD; Svenja Rauch; Frank Theisohn; Paolo Ferrero; Serban Stoica, FRCS; Maciej Matuszewski, MD; Patrick Yiu; Mohamad Bashir, MD, PhD, MRCS; Fabrizio Ceresa; Francesco Patane, MD; Ruggero De Paulis, MD; Ilaria Chirichilli MD; Mauro Masat, MD; Carlo Antona, MD; Monica Contino, MD; Andrea Mangini, MD; Claudia Romagnoni, MD; Francesco Grigioni, MD, PhD; Rubina Rosa; Yutaka Okita, MD; Takeshi Miyairi, MD; Takashi Kunihara, MD; Dave Koolbergen, MD, PhD; Jos Bekkers, MD, PhD; Robert Klautz, MD, PhD; Thomas Van Brakel, MD, PhD; Bardia Arabkhani, MD, PhD; Gianclaudio Mecozzi, MD; Ryan Accord, MD; Guido van Aarnhem, MD; Marek Jasinski, MD, PhD; Vladislav Aminov; Mihail Svetkin; Adrian Kolesar, MD; František Sabol, MD; Tomas Toporcer; Ignacio Bibiloni; Gregorio Rábago, MD; Virginia Alvarez-Asiain; Amaia Melero; Rafael Sadaba, MD; José Aramendi, MD; Alejandro Crespo, MD; Carlos Porras, MD; Arturo Evangelista Masip, MD; Joseph Bavaria, MD, PhD; Rita Milewski, MD, PhD; Patrick Moeller; Isaac Wenger; Maurice Enriquez-Sarano, MD; Christine Leon; Jean Marc Marnette, MD; Vincent Doisy MD; Fabrice Wautot, MD; Thierry Bourguignon, MD; Duke Cameron, MD; Edward Chen, MD. 
(AR) with or without aortic dilatation. The first attempts go back to the early sixties and two important surgical procedures-remodeling and reimplantation-appeared in the late 1980s and early 1990s, which gave rise to new tools for the treatment of complex disorders of the aortic valve and root (1). In the current era, considerable variety in repair techniques exist: reimplantation with straight or sinus tube grafts, remodeling techniques with or without additional annuloplasty with a suture or ring, usage of various patch materials, different commissural orientations after bicuspid aortic valve repair and the use of systematic measurement tools of effective height.

Aortic valve repair is usually performed in specialized centers as these procedures require a steady number of cases to maintain expertise and skills, noting that the incidence of potential patients is low. Most publications originate from single centers and report only mid-term results (2). Not all valves are good candidates for aortic valve repair and additional treatment options are mechanical valve replacement, the Ross procedure and aortic wrapping [e.g., Personalized External Aortic Root Support (PEARS)].

To help surgeons and patients with choosing the best treatment option, ideally long-term outcome of lots of patients after different therapies should be compared. To achieve this, uniform outcome evaluation measurements, multi-center data and patient-centered information is needed. This will provide a firm base for a coherent discourse for cardiologist and cardiothoracic surgeons treating and informing these patients.

With this in mind, the Aortic Valve (AV) Insufficiency and ascending aorta Aneurysm InternATiOnal Registry (AVIATOR) was established. The AVIATOR community is one of the Valve Research Networks (VRN) of the Heart Valve Society (HVS) (3). In the AVIATOR registry, a longitudinal disease specific patient cohort is followed, meaning all patients with isolated aortic valve insufficiency (including congenital mixed aortic valve disease) and/or ascending aorta aneurysm (including root and/or supra coronary aorta and aortic dissection) are eligible. This is irrespective of whether patients undergo aortic valve repair or replacement. The registry is open to any center taking care of these patients, thus not for the highly specialized centers only. Participation is free, at least one person of the team needs to be a member of the HVS. All information to join is available on: http://heartvalvesociety.org/AVIATOR.

The ultimate goal is to embrace the complete disease trajectory of AR from diagnosis till death by clinical and echocardiographic follow-up once the diagnosis has been made. The adult surgical AVIATOR database is established and has been enrolling patients since August 2013. AVIATOR-kids (pediatric surgery) is in progress and enrollment will follow in the near future. The same holds for the AVIATOR medical registry, which will enable the study of the natural history of AR and evaluation of the guidelines.

The AVIATOR registry collects detailed information of perioperative cusp analysis and cusp repair strategy. Furthermore, the intention to repair the valve is asked at two points in time: preoperatively, based on echocardiography and preoperatively, after cusp analysis. In combination with information on long-term durability of the repair, this could shed light on which patients are good candidates for repair and which are not and will thus enable tailor-made treatment strategies. Participating centers are asked to update clinical follow-up (bi-)annually. Obviously, it is not just survival, but the relief of symptoms, avoidance of long-term disability and a sense of well-being that are likely to be the most important and highly valued outcomes for patients. At present, the AVIATOR registry embraces the uniform outcome evaluation measures according to the guidelines for reporting mortality and morbidity after cardiac valve interventions by Akins et al. (4). The addition of quality of life assessment to the registry will be an important goal for the future. The AVIATOR registry is a voluntary registry and leans on the effort participants are willing to put in. Data completeness can be a risk and will be the main focus the coming years. By hiring a full-time data manager, the AVIATOR initiative will professionalize further.

The AVIATOR registry originated in Europe and especially European centers are enrolling patients at this stage. They are responsible for the inclusion of $5,348(89.2 \%)$ patients, followed by North America with $457(9.5 \%)$ patients, Africa $42(0.8 \%)$ patients and Asia $16(0.5 \%)$ patients. Valve repair is the dominant operation with $88 \%$ versus $12 \%$ replacements. The reconstructive surgery includes isolated valve repair in $27 \%$, partial root or tubular aorta replacement plus valve repair in $23 \%$ and valve-sparing root replacements in $50 \%$. Replacements include isolated valve replacement in $22 \%$, tubular aorta plus aortic valve replacement in $19 \%$ and root plus valve replacement (Bentall) in 59\%. Most of the expert centers on aortic valve repair are including all their patients in the AVIATOR registry.

The AVIATOR initiative is a unique effort in sharing data worldwide. It has grown exponentially the last 5 years 
from its birth in 2013 till now. The first descriptive analysis of the AVIATOR population shows the variation of patients and reveals potential biases within the registry (e.g., repair versus replacement, high versus low volume centers and European countries versus other regions). The AVIATOR data-platform catalyzes new initiatives within the HVS. To evaluate prosthetic aortic valve replacement in patient with $\mathrm{AR}$ or stenosis a new initiative has arisen: the LEOPARD registry.

By combining surgical experience from multiple centers and applying uniform definitions of echo and outcome parameters, it should become possible to provide a solid evidence base for tailored treatment in the individual patient with aortic valve regurgitation and/or dilatation of the ascending aorta. Long-term commitment of surgeons into clinical evaluation is key to provide solid medical evidence and to deliver the best treatment to our patients according to current medical knowledge.

\section{Acknowledgments}

None.

Cite this article as: de Heer F, Lansac E, El-Hamamsy I, Pibarot P, De Kerchove L, El Khoury G, Schäfers HJ, Takkenberg JJ, Kluin J; on behalf of the Aortic Valve Repair Research Network Investigators. The AVIATOR registry: the importance of evaluating long-term patient outcomes. Ann Cardiothorac Surg 2019;8(3):393-395. doi: 10.21037/ acs.2019.04.08

\section{Footnote}

Conflicts of Interest: The authors have no conflict of interest to declare.

\section{References}

1. Fok M, Shaw M, Sancho E, et al. Aortic Valve Repair: A Systematic Review and Meta-analysis of Published Literature. Aorta (Stamford) 2014;2:10-21.

2. Arabkhani B, Mookhoek A, Di Centa I, et al. Reported Outcome After Valve-Sparing Aortic Root Replacement for Aortic Root Aneurysm: A Systematic Review and Meta-Analysis. Ann Thorac Surg 2015;100:1126-31.

3. de Heer F, Kluin J, Elkhoury G, et al. AVIATOR: An open international registry to evaluate medical and surgical outcomes of aortic valve insufficiency and ascending aorta aneurysm. J Thorac Cardiovasc Surg 2018. [Epub ahead of print].

4. Akins CW, Miller DC, Turina MI, et al. Guidelines for reporting mortality and morbidity after cardiac valve interventions. J Thorac Cardiovasc Surg 2008;135:732-8. 